\title{
EFECTOS ESPERADOS DE LOS RIESGOS GLOBALES EN LA ECONOMÍA PERUANA (2017)
}

\author{
Jesús Chávez Villarroel* \\ Universidad Nacional Mayor de San Marcos \\ jesus.chavez2@unmsm.edu.pe
}

Fecha de recepción: agosto de 2017 Fecha de aceptación: diciembre de 2017

ReSUmen: En este artículo se identificarán y analizarán los efectos-riesgos locales que devendría de la realización de los llamados riesgos globales. Los riesgos globales son vistos como amenazas que en conjunto con la vulnerabilidad local, genera los efectos y/o riesgos locales, los cuales se concentran en los sectores económicos y sociales. Para este estudio se hizo uso del método hipotético-deductivo con apoyo de métodos cuantitativos ligados a la matemática y estadística-teoría de grafos y métricas de relaciones e influencias. Así, se utilizó como bases de datos el acopio de los riesgos globales del año 2017, en conjunto con las bases de los índices de vulnerabilidad local para el país; encontrándose una fuerte relación e influencia de las tendencias sobre los riesgos globales, de los riesgos globales sobre la vulnerabilidad y de las tendencias y riesgos globales sobre los efectos-riesgo local. Visto de ese modo, se establecerá que el Perú posee un riesgo de grado medio en una escala de baja a alta, y este grado o nivel se ve influenciado por la relación de los riesgos globales y vulnerabilidad.

Jesús Chávez Villarroel es docente de la Facultad de Economía de la UNCP. Asimismo, es tesista en el Programa del Doctorado en Gestión Económica Global de la Facultad de Ciencias Económicas de la Universidad Nacional Mayor de San Marcos. 
JESÚS CHÁVEZ VILLARROEL

Palabras clave: Tendencia global, riesgo global, vulnerabilidad, efectoriesgo local, grado, comunidad, intermediación, centralidad.

\section{EXPECTED EFFECTS OF GLOBAL RISKS IN THE PERUVIAN ECONOMY (2017)}

ABSTRACT: This article identifies and analyzes the local risk-effects that would arise from the realization of the so-called global risks. Global risks are seen as threats that together with local vulnerability local effects and / or risks are generated, which are Concentrated in the economic and social sectors. For this study we used the hypothetical - deductive method with the support of quantitative methods linked to mathematics and statistics - theory of graphs and metrics of relations and influences, for this was used as databases the collection of global risks of 2017. In conjunction with the bases of the local vulnerability indexes for the country; There is a strong relationship and influence of trends on global risks, global risks on vulnerability and global trends and risks on local risk effects, finding that Peru has an average risk on a scale of low to High, and this degree or level is influenced by the ratio of global risks and vulnerability.

KeYwords: Global trend, global risk, vulnerability, local risk-effect, degree, community, intermediation, centrality.

\section{Introducción}

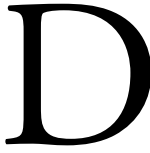

esde hace más de una década, los informes del Foro Económico Mundial han centrado su atención en la evolución de los riesgos globales y sus profundas interconexiones (World Economic Forum, 2017). Entre ellas, subrayando el potencial de las tendencias persistentes a largo 
plazo, destacan la desigualdad o la creciente polarización social y política, las cuales agravan los riesgos asociados. Dichas tendencias presentaron un alto protagonismo durante el 2016, año en el que el creciente descontento político se hizo evidente en muchos países del mundo.

Algunas señales más claras de quiebre o rotura se han producido en los países occidentales. Con la votación en Reino Unido a favor de abandonar la Unión Europea y la victoria de Donald Trump en las elecciones presidenciales de los Estados Unidos de Norteamérica, en todo el mundo se están observando reacciones negativas ante ciertos elementos del statu quo nacional e internacional. Tal panorama no es ajeno a los países o economías con mercado emergente, especialmente los latinoamericanos como Perú, cuyas relaciones con la economía globalizada se dan principalmente a través de sus exportaciones de materias primas e importaciones de bienes de capital, haciendo que el país esté sujeto a la dinámica de la economía mundial y expuesto a los riesgos globales como una amenaza o peligro (Finanzas, 2016). Visto de esta forma, es pertinente e importante establecer los efectos y/o riesgos locales que emergerían o se activarían a partir de la realización de uno o más riesgos globales.

En este artículo se propone el desarrollo de un estudio de relaciones e influencias estadísticas, al establecer la relación entre los riesgos globales (derivados de una economía globalizada) frente a los riesgos internos propios de una economía emergente como es la economía peruana. Para ello se identificarán, a través del empleo de fuentes de organismos globales como el Foro Económico Mundial, los principales y relevantes riesgos globales. A su vez, se identificarán los riesgos internos o propios de una economía emergente, usando documentos o fuentes de datos propios a la economía. Para establecer las relaciones entre ambos tipos de riesgos se hará uso de un enfoque lógico deductivo. Se usará como medios diversas teorías de la sociología, economía y, como instrumento de análisis, métodos y técnicas 
JESÚS CHÁVEZ VILLARROEL

de la matemática y estadística. Todo será usado bajo un enfoque holista, en especial de la teoría de grafos y el análisis de redes sociales.

\section{Marco Teórico}

\subsection{Globalización y riesgos}

La globalización como una "teoría" se enfoca en el grado de interdependencia, en campos, regiones y países del mundo, sobre la base de los adelantos tecnológicos en el campo de las comunicaciones y sus consecuencias económicas y socioculturales que de ella se derivan (Reyes, 2001). Así, la teoría de la globalización tiene como propósito la interpretación de los eventos que tiene lugar en los campos del desarrollo, la economía mundial o global, los escenarios sociales y las influencias culturales y políticas. Esto provoca la existencia de un mayor grado de interrelación-dependencia entre las sociedades, presentándose, también, aspectos fundamentales en los eventos económicos y sociales que están teniendo lugar.

Por otro lado, la globalización como proceso comprende una creciente internacionalización o mundialización del capital financiero, industrial y comercial, nuevas relaciones políticas internacionales y la aparición de la empresa transnacional como una necesidad del reacomodo del sistema capitalista de producción. Por otro lado, es el intercambio de capital económico un proceso económico, político y social que está siendo tomado con mayor énfasis en los países en desarrollo. Así, se toma como objetivo el logro del crecimiento económico y disminución de la pobreza; lo cual no es concebido como un modelo de desarrollo económico y mucho menos del desarrollo social, "planteándose un marco regulatorio de las relaciones internacionales entre los países; imponiéndose una ideología 
según la cual no hay alternativa al neoliberalismo y a la globalización" (Mateus, Julian, \& Braset, 2002, p. 55).

\subsection{Economía emergente y riesgos}

Las multinacionales emergentes de Latinoamérica ocupan ya muchos de los primeros puestos del ranking mundial de empresas por capitalización bursátil y han protagonizado algunas de las operaciones de fusión y adquisición más importantes de los últimos años (Casonova, 2010). La complacencia siempre es un problema y éxito que los emergentes han demostrado que no están exentos de riesgos de cara al futuro. Por ese motivo, "es un gran reto saber gestionar en la abundancia" (Gallego, 2011, p. 32).

La gran crisis financiera global llevó a la mayoría de los bancos centrales a relajar considerablemente sus políticas monetarias. De esa forma, hicieron uso de estrategias no convencionales en algunas naciones avanzadas. Al mismo tiempo, para evitar riesgos asociados con los auges de las entradas de capital, requirieron la aplicación de estrategias que permitieran prevenir y manejar el surgimiento de problemas en la economía y el sistema financiero. Fueron estas "medidas [las] que desalentaron el influjo de capital ajustando a la baja las tasas de interés de política monetaria, controles explícitos de capital, restricciones a la inversión extranjera o al financiamiento externo de corto plazo, financiamiento de proyectos de inversión que no representen una fragilidad financiera en el futuro" (Sánchez Gonzales, 2001, p. 5).

Para las economías emergentes, el entorno internacional las afecta con la volatilidad en los precios de las materias primas. Las tasas de interés son más altas en estos países, pues su inflación también lo es. Asimismo, sostienen "el tipo de cambio al alentar la entrada de capitales y, debido a ello, acudiendo muchas veces al control de capitales" (Gaba, 2013, p. 4). 


\subsection{La sociedad global y el riesgo}

En la Sociología del Riesgo se afirma lo siguiente: "Lo que no está previsto lo registramos como casualidad, pero no puede ser dejado al azar, lo cual tiene que mostrar su propio orden” (Acevedo \& Vargas, 2000, pp. 14-15). En este marco, la clave son las decisiones, las cuales a su vez son las causas desencadenantes y pueden ser identificadas. Por otro lado, también se puede tomar en cuenta que “(...) las personas no calculan los riesgos sino que se comportan como lo esperan los grupos de referencia relevantes, o tal como han sido socializados” (Luhmann, 1993, p. 31). Así, el cálculo de riesgos es temporal, el daño puede ser evitado. Sin embargo, puede aceptarse acciones riesgosas que, por lo tanto, implique un daño, siempre y cuando se justifique de acuerdo con su magnitud y probabilidad de ocurrencia.

Más aún, los conflictos sociales y los peligros asociados al desarrollo de nuevas tecnologías se van incrementando y transforman el tema de la aceptación de los riesgos y de las nuevas tecnologías en un tema mayor e ineludible. De igual modo, el concepto de riesgo ha ampliado su relevancia e importancia y ha terminado por traspasar la temática de la seguridad de las nuevas tecnologías (Paulus, 2004). Esto ha hecho emerger cada vez más los riesgos asociados al uso de las nuevas tecnologías en el proceso productivo de la economía mundial.

Asimismo, la sociedad moderna se caracteriza por un imperio de efectos colaterales desarrollados a través del operar inconexo de los diversos subsistemas de la sociedad moderna, y encuentra su punto principal en el déficit estructural de racionalidad, como resultado de la pérdida de visión global de los problemas que la afectan (Beck, 1993). Contrariamente a Luhmann (1993), los principios de diferenciación que estabilizan y viabilizan el desarrollo de la sociedad, dificultan y obstaculizan el tratamiento de los 
problemas globales y estos expanden de manera incontrolable sus riesgos y peligros. Por otro lado, Beck precisa: "la novedad es que la fuente de los peligros no se encuentra en los entornos de la actividad social, sino en las mismas operaciones sociales y sus amenazas son auto configuradas" (2000, p. 25). Para el autor, la sociedad ha de potenciar su aproximación multidimensional a estas amenazas, dado que han sido las aproximaciones parciales las que lo han probabilizado.

Después, la conceptualización del riesgo, en esta sociedad del riesgo, se articula sobre la base de los siguientes factores: (a) depreciación de la naturaleza y la cultura; (b) la crisis de la controlabilidad; y (c) el deterioro, descomposición y desencanto de quienes han respaldado a las sociedades basadas en la dimensión económica (Paulus, 2004). De otra parte, Ugalde (2012) describe el riesgo global como la triada compuesta de los siguientes elementos: (a) escenario (peligro o amenaza); (b) posibilidad (probabilidad de ocurrencia); y (c) consecuencia (efecto o impacto). Estos son componentes que se asocian a la vulnerabilidad pues de esta es posible derivar la magnitud del efecto o impacto.

Cabe decir que esta referencia se ha convertido en la más citada de las últimas tres décadas con relación al riesgo. Por otro lado, de acuerdo con Yamin (2013), el riesgo está implícito en todas las dimensiones de nuestras vidas y es parte inseparable de nuestras acciones. Puede entenderse, entonces, como la posibilidad de sufrir pérdidas significativas o resultados adversos.

Desde la perspectiva de peligro, amenaza y daño, el riesgo está relacionado tanto con la probabilidad de que un evento adverso se presente como con su severidad o potencial de causar daño (Maskrey, 1993). También está íntimamente relacionado con la percepción humana. Se percibe claramente cuando las actividades cotidianas se pueden ver interrumpidas por un evento adverso que parece inesperado o excepcional. 


\subsection{Modelo teórico}

En el presente texto, el modelo teórico para el riesgo global ${ }^{1}$, y su efecto esperado en economías emergentes o en desarrollo, se ha basado en las publicaciones y propuestas teóricas de Niklas Luhmann (2000), Urlich Beck (2000), Anthony Giddens (1999, 2000) y Andrew Maskrey (2000). Se partirá, además, de la propuesta teórica de N. Luhmann y A. Giddens, el uso de la ciencia y la tecnología sobre la naturaleza y el contexto social actual en el tiempo. Por otro lado, se apelará a la toma de decisiones de los diferentes subsistemas funcionales (productivo, económico-financiero, político, entre otros), en ambientes de constante incertidumbre, forzados por el crecimiento económico y la comunicación. Todos estos implican, en la emergencia del riesgo global, un riesgo manufacturado o riesgo interno al sistema global, que se mimetiza en muchos de los casos con riesgos externos (mayormente, riesgos naturales). Así, el riesgo global se especifica mediante la siguiente ecuación:

$$
R_{g}=f(y, d f, d e, \varepsilon)
$$

\section{Donde:}

$R_{g} \quad$ : Riesgo global. Medido por la verosimilitud y severidad.

$Y$ : Variación porcentual del producto como indicador del crecimiento económico.

1 Un riesgo global es un evento o condición inciertos que, de ocurrir, pueden tener un importante efecto negativo para varios países o sectores en los siguientes diez ańos. La identificación y valoración se basa en las perspectivas de expertos y dirigentes mundiales. Para más información, ver el siguiente enlace: https://www.weforum.org/es/ agenda/2015/01/cuales-son-los-riesgos-globales-que-enfrentamos-en-el-2015/ 
Df : Diferenciación funcional. Medido por el número de subsistemas funcionales.

De : Decisiones en innovación, inversión, políticas, entre otros. Medido por el número de decisiones tomadas.

$\varepsilon \quad$ : Término de error, asociado a un contexto de incertidumbre.

Este riesgo es transmitido o distribuido a otros espacios o tiempos (economías emergentes o en desarrollo) a través de las inversiones extranjeras, la comunicación con soporte en la ciencia y tecnologías productivas (Beck, 2002). La ecuación que representa este proceso viene dada de la siguiente forma:

$$
\mathrm{T}=f(I E D, C, \varepsilon)
$$

Donde:

$T$ : Transmisión del riesgo global. Variable de flujo medido por el número de Riesgos Globales transmitidos.

IED : Variación de la Inversión Extranjera Directa en el país o economía emergente o en desarrollo.

C : Flujos de comunicación, medido por la cantidad de información que se transmite (bits de información).

$\varepsilon \quad$ : Término de error, asociado a un contexto de incertidumbre.

Para el caso de la recepción del riesgo global y medición de los efectos esperados, esta se mide como la emergencia de nuevos riesgos. Esto es, un riesgo global (identificado) que se presenta como amenaza o peligro y causa la emergencia o percepción de uno o más riesgos, lo cual está sujeto, como variables intervinientes, a los activos y personas expuestas y la vulnerabilidad (Maskrey, 1993) como característica intrínseca al país o economía emergente o en desarrollo. Aunque, "no se es vulnerable si 
no se está expuesto", (Cardona, 1995, p. 25), pues se adapta la propuesta expresando el efecto-riesgo local como una "relación" ${ }^{2}$ del riesgo global (amenaza o peligro) (Coburn \& Spence, 1992) y la vulnerabilidad como una medida relativa de la capacidad de la población de absorber y recuperarse de un daño o pérdida determinada. Este indicador en los términos de vulnerabilidad vendría dado por la siguiente expresión:

$$
\left.R_{l, e}\right|_{t}=\mathcal{R}\left(T_{g, i}, R_{g, i} ; V_{e} ; \varepsilon\right)_{i}
$$

\section{Donde:}

$\mathcal{R}$ : Indica una relación.

$R_{L, e}$ : Riesgo Local específico en el tiempo " $t$ ". Como indicador de efecto esperado e indicado por la verosimilitud y severidad.

$T g, i$ : Tendencia Global específica en la categoría “ $i$ ”.

$R_{g, i}$ : Riesgo global específico en la categoría “ $i$ ”.

$V_{e} \quad$ : Vulnerabilidad. Características cualitativas que representan las capacidades disminuidas del sistema (país o economía emergente o en desarrollo) o condición socialmente producida. Se mide como un índice específico de los diferentes tipos de vulnerabilidad.

$\varepsilon \quad$ : Término de error, asociado a un contexto de incertidumbre local.

De este modo, el efecto-riesgo local está relacionado con las tendencias globales como factor implicante sobre el riesgo global; el "riesgo global" como la amenaza o peligro y, por último, la "vulnerabilidad" para Perú, determinada por la exposición de activos o personas, resiliencia, recuperación, aprendizaje y

2 Se propone una relación, pues, de un riesgo global, podrían emerger cero o más riesgos locales. Esto haría que la relación no se ajuste a una función. 
adaptación (Ratick, 1994). Adicionalmente, la secuencia inicia en las tendencias globales hacia los riesgos globales y de estos hacia la vulnerabilidad. Dicha relación es la que implica la magnitud del efecto-riesgo local.

\section{Metodología}

Este estudio se enfoca en el análisis de las relaciones e influencias de las tendencias globales, riesgos globales, vulnerabilidad y efectos-riesgos locales para el Perú al año 2017. Por lo anterior, se presenta y describe las tendencias, riesgos globales y vulnerabilidad interna. A partir de los riesgos globales, y haciendo uso de diagramas causales, se identificó los efectos esperados y riesgos locales. A su vez, al hacer uso de la teoría de grafos en su versión "Análisis de Redes Sociales", se realizó el análisis de relaciones e influencias.

De acuerdo al estudio realizado, y respecto a la hipótesis formulada, se identificarán las siguientes variables:

- Variables dependientes:

- Efecto-Riesgo Local (Índice de Riesgo).

- Variables independientes:

- Tendencias globales.

- Riesgos globales (listado predefinido en el informe World Economic Forum).

- Vulnerabilidad: Fragilidad, exposición, resiliencia.

El estudio ha sido de tipo retrospectivo, relacional y probabilístico, pues se identificaron los efectos-riesgos locales a partir de los riesgos globales y además 
JESÚS CHÁVEZ VILLARROEL

se estimó un índice de ocurrencia en términos de verosimilitud. Igualmente, el estudio tuvo un enfoque cuantitativo, puesto que en la investigación se manejó u operó con datos susceptibles de ser contados, pesados o medidos, los cuales tendrán que utilizar una metodología cuantitativa. Las unidades de análisis derivarán de la comunidad global (conjunto de economías en la globalización) y la economía con mercado emergente bajo estudio será Perú en el año 2017.

Cabe agregar que las técnicas para el recojo de datos provienen de un proceso de acopio o, mejor dicho, el proceso que va desde la identificación, operacionalización de variables, definición de los indicadores y sus respectivas fuentes de obtención. Dichos documentos e informes han sido publicados por el World Economic Forum, bases estadísticas del FMI, Banco Mundial, entre otros. Para el caso del Perú, se tiene fuentes del BCRP, MEF, INEI, CEPLAM, entre otros. Por último, para establecer los principales riesgos globales con influencia significativa en el país, se utilizó matrices de relaciones y el análisis del grafo respectivo. Una vez identificados los riesgos globales para el estudio, se procedió a identificar las relaciones de estos con la economía del Perú.

\section{Resultados}

\subsection{Los riesgos globales 2017}

En países occidentales como, por ejemplo, Reino Unido y su salida de la Unión Europea o la elección a la presidencia de los Estados Unidos de Norteamérica hacia Donald Trump, estos eventos aumentan la incertidumbre en la comunidad mundial. Aunada a ello, crece la desigualdad, en especial la disparidad creciente de los ingresos y riqueza, aumento del populismonacionalismo, fracturas o quiebres de las estructuras sociales y reformas 
en los mercados capitalistas. Al mismo tiempo, se originan cambios en las actitudes frente a la orientación social, raza, multiculturalismo, protección ambiental y la cooperación internacional; el deterioro del empleo (en términos de cantidad y calidad) que deviene de los cambios tecnológicos y traslado de la producción a países o economías menos reguladas.

El Fórum Económico Mundial, identifica 30 riesgos (ver Figura 1), los cuales vienen clasificados dentro de diversas materias (económica, ambiental, social, geopolítica y tecnológica). Al mismo tiempo, se le asocian medidas tanto en su probabilidad de ocurrencia (rango de 1, tomado como poco probable, hasta 7 , considerado como muy probable) e impacto (rango de 1 a 7, que se interpreta desde mínimo, menor, moderado, severo hasta catastrófico). Por otro lado, estos riesgos son divididos en cuatro cuadrantes (intersección de las medias de probabilidad e impacto).

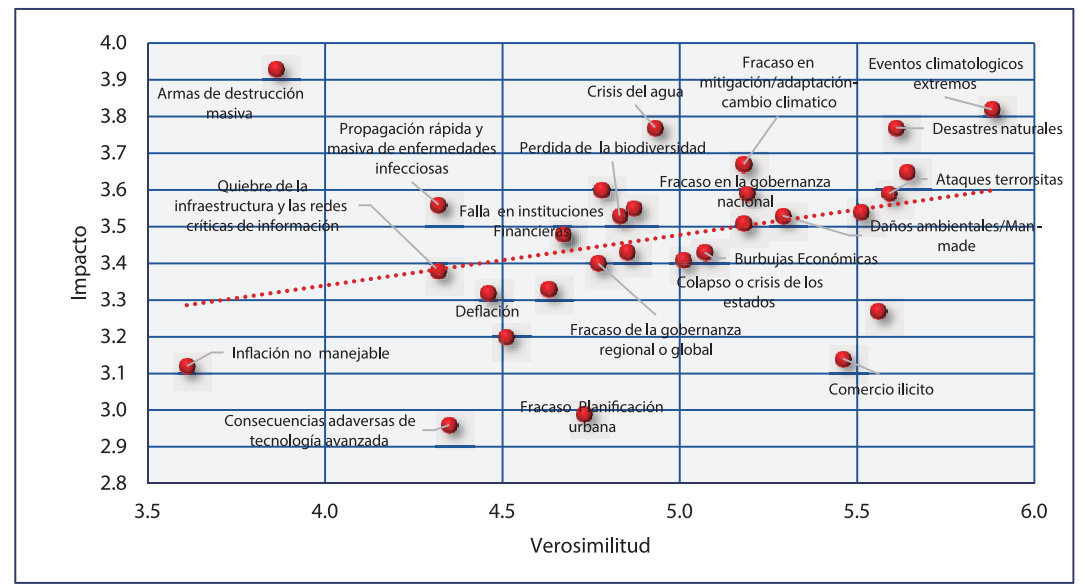

Figura 1. Riesgos globales y sus pérdidas económicas - 2017. Adaptado de "The Global Risks. Report 2017,” por World Economic Forum, 2017. 
Asimismo, en la Figura1, los riesgos de mayor probabilidad y mayor impacto (de mayor a menor) son los siguientes: (a) eventos climatológicos extremos, (b) desastres naturales, (c) fracaso en los programas de mitigación-adaptación al cambio climático, (d) desastres ambientales que devienen de la participación del hombre (en especial los relacionados a los procesos productivos), (e) crisis por la falta de agua dulce, (f) altos flujos migratorios involuntarios, (g) conflictos interestatales, (h) oleada de ataques terroristas e (i) aumento del desempleo-subempleo. Aunque, en este mismo cuadrante, se presenta un riesgo tecnológico (cyberataques a plataformas informáticas de países, instituciones y/o empresas claves).

\subsection{Indicadores de vulnerabilidad - fragilidad, exposición y resiliencia}

A continuación, se presentarán y se describirán los indicadores de vulnerabilidad. Estos indicadores han sido obtenidos de dos fuentes: FM Global $^{3}$ (Commercial Property Insurance) - Oxford Métrica ${ }^{4}$ e INFORM ${ }^{5}$ (INdex FOr Risk Managament). A partir de estas fuentes se acopia los índices de vulnerabilidad para el caso del Perú.

Para comenzar, FM Global construye índices de resiliencia compuesto por varios factores (económico, calidad de gestión y cadena de suministro) dado por la posición (de un total de 130 países) y el score (puntaje del 0 al 100). De igual modo, mientras el score se aproxime a 100, mejor son las condiciones para afrontar una amenaza o peligro. Por el contrario, cuando el score esté más cerca a cero, las condiciones para afrontar una

3 http://www.fmglobal.com

4 http://www.oxfordmetrica.com/en/web/oxford-metrica.aspx.

5 http://www.inform-index.org/. 
amenaza o peligro son mínimas o nulas. Para el caso de las métricas de INFORM, estos vienen dados en un rango de 0 a 10. En estas métricas, cuando el índice esté más cerca de 10, las condiciones expuestas o fragilidad contribuyen con los efectos o impactos negativos en la realización de una amenaza o peligro.

Posteriormente, se describirá los índices de vulnerabilidad calculados por INFORM, índice que ubica al país en riesgo medio — 4.1 de 0 a 10—. Así, la exposición a peligros o amenazas, con un valor de 5.2, valor sobre el promedio, mantiene al país en una posición (48 de 191 países) altamente expuesta a peligros o amenazas determinadas por las características geográficas del país. Por el lado de la fragilidad, el valor es bajo en la posición 105 (al contrario del índice FM Global, la posición 191 es la mejor y, la primera, la peor en condiciones de riesgo). En cuanto a la capacidad de recuperación, su valor de 4.6 lo ubica en un rango bajo con una posición 90 en el ranking de los 191 países que componen la base del índice INFORM, índices que guardan coherencia con los calculados por FM Global. Todos estos datos se ejemplificarán en la Tabla 1.

Tabla 1

Perú: Indice de Resiliencia Global - Cadena de Suministro - 2017

\begin{tabular}{|l|r|r|r|l|}
\hline \multicolumn{1}{|c|}{ INFORM Risk } & Value & Clase & \multicolumn{1}{c|}{ Rank } & Trend (3 years) \\
\hline Índice de Riesgo & 4.1 & Medio & 74 & Se mantiene \\
\hline Amenaza y Exposición & 5.2 & Alto & 48 & Se mantiene \\
\hline Vulnerabilidad (Fragilidad) & 2.8 & Bajo & 105 & Disminuye \\
\hline $\begin{array}{l}\text { Falta de capacidad de } \\
\text { Recuperación }\end{array}$ & 4.6 & Bajo & 90 & Se mantiene \\
\hline
\end{tabular}

Nota. Adaptado de "Index for Risk Management - Results 2017," por Index for Risk Management, 2017. 
En la misma línea, se hablará de las distintas dimensiones que componen el índice INFORM (ver Tabla 2), las cuales son de exposición (sismos, inundaciones, entre otros). Más aún, se observará que son los sismos y tsunamis los que muestran valores muy cercanos a 10, pues Perú, como país, se ubica en el llamado Cinturón o Anillo de Fuego del Pacifico ${ }^{6}$. El índice referido a las inundaciones, también tomará un valor (6.5) sobre el promedio, eventos que han venido sucediendo con más frecuencia y con menor rango del periodo de ocurrencia, debido a que Perú ya enfrentó estos embates asociados en gran medida al cambio climático, factor que se presenta como una tendencia en el campo de los riesgos globales.

Por otro lado, la desigualdad y las fallas en gobernanzas ubican al país en un rango de vulnerabilidad media, dos factores que caminan juntos, pues mientras la desigualdad social y económica viene aumentando o manteniéndose, los problemas o movilizaciones sociales se acrecientan. Se convierte, entonces, en pretexto de muchos ofrecimientos, aumento de partidos populistas que cuando llegan al gobierno retraen en sus capacidades de generación de renta a los grupos mayoritarios ubicados en los estratos bajos, lo cual da cabida a la filtración de "políticos" que desmedran la gestión pública produciéndose así fallas en la gobernanza (incapacidad de gestión, corrupción, perdida de institucionalidad, entre otros).

6 El Cinturón de Fuego del Pacífico (o Anillo de Fuego del Pacífico) está situado en las costas del océano Pacífico y se caracteriza por concentrar algunas de las zonas de subducción más importantes del mundo, lo que ocasiona una intensa actividad sísmica y volcánica en las zonas que abarca. Incluye a Chile, Argentina, Bolivia, Perú, Ecuador, Colombia, Panamá, Costa Rica, Nicaragua, El Salvador, Honduras, Guatemala, México, Estados Unidos, Canadá, luego dobla a la altura de las islas Aleutianas y baja por las costas e islas de Rusia, Japón, Taiwán, Filipinas, Indonesia, Malasia, Timor Oriental, Brunéi, Singapur, Papúa Nueva Guinea, Islas Salomón, Tonga, Samoa, Tuvalu y Nueva Zelanda. 


\subsection{Tendencias globales}

Para el Foro Económico Mundial, una tendencia es un patrón de largo plazo que evoluciona y podría contribuir en la amplificación de los riesgos globales. Ahora bien, en el caso de las tendencias de acuerdo con la encuesta 2017 del Foro Económico, por su incidencia con los riesgos globales, se ha identifica de 13 de ellas. Estas son las que siguen: (a) envejecimiento poblacional, (b) cambios en la gobernanza internacional, (c) cambio climático, (d) degradación del medio ambiente, (e) aumento de la clase media en economías con mercados emergentes, (f) aumento del nacionalismo, (g) polarización social, (h) aumento de enfermedades crónicas, (i) dependencia cibernética, (j) aumento y movilidad geográfica, (k) aumento de la desigualdad (ingresos), (l) cambio en la estructura de poder y $(\mathrm{m})$ aumento de la urbanización.

\subsection{Selección de los riesgos globales para análisis}

Para efectivizar la metodología y contrastación de las hipótesis, se seleccionó un subconjunto de riesgos globales bajo tres criterios. El primero señala que tales riesgos deben situarse sobre el cuadrante I (cuadrante I: bajo la media de la probabilidad de ocurrencia y bajo la media del impacto, medido como una porción del producto mundial), lo cual garantiza analizar los riesgos de mayor probabilidad e impacto bajo la ocurrencia de estos. Por otro lado, el segundo criterio es la percepción del riesgo global en relación a limitación para la inversión o negocios en Perú, seleccionándose aquellos riesgos que poseen una mayor percepción limitante en los negocios. El tercer criterio, y a la vez el más importante, es la asociación con los índices de 
JESÚS CHÁVEZ VILLARROEL

vulnerabilidad dado por la exposición y fragilidad y los índices de resiliencia (ver Tabla 2).

Tabla 2

Perú: Indices de Riesgo, Amenaza y Exposición, Vulnerabilidad y Falta de Recuperación - 2017

\begin{tabular}{|l|r|r|}
\hline \multicolumn{1}{|c|}{ INFORM Risk } & Value & \multicolumn{1}{c|}{ Clase } \\
\hline Índice de Riesgo & 4.1 & Medio \\
\hline Amenaza y Exposición & 5.2 & Alto \\
\hline Natura I & 7 & Muyalto \\
\hline Hum ana & 2.2 & Bajo \\
\hline VuInerabilidad (Fragilidad) & 2.8 & Bajo \\
\hline Socio Económ ica & 2.3 & Bajo \\
\hline Grupos VuInerables & 3.3 & Medio \\
\hline Faltade capacidad de Recuperación & 4.6 & Bajo \\
\hline Institucional & 4.8 & Bajo \\
\hline Infraestructura & 4.3 & Medio \\
\hline
\end{tabular}

Nota. Adaptado de "Index for Risk Management - Results 2017," por Index for Risk Management, 2017.

Ahora bien, los criterios mencionados anteriormente, fueron ejecutados a través de un conjunto anidado de sentencias del tipo "si, entonces" en una hoja electrónica, de lo cual se seleccionaron 14 riesgos que se asocian con las medidas de vulnerabilidad del país: (a) seis riesgos globales económicos, (b) tres ambientales, (c) dos sociales, (d) dos geopolíticos y (e) un tecnológico. Entre los riesgos globales seleccionados (ver Tabla 3), se anota lo siguiente: (a) la realización de burbujas económicas, (b) crisis fiscal, (c) desempleo, (d) shock en los precios de los combustibles y (e) comercio ilícito. En el tema ambiental, se seleccionaron los siguientes riesgos: (a) la posible ocurrencia de eventos climatológicos extremos, (b) fracaso en la mitigación del cambio climático y (c) desastres naturales. En cuanto a lo sociopolítico, los riesgos son los que siguen: (a) el fracaso de la planificación 
urbana, (b) crisis por el agua dulce, (c) fracaso de la gobernanza nacional y (d) colapso de los estados. Por último, dentro de los tecnológicos, se seleccionó los posibles incidentes en nivel masivo de fraude o robo de datos de los distintos sistemas que posee y apoyan el proceso productivo mundial. A continuación, la Tabla 3 ejemplificará los datos mencionados.

\section{Tabla 3}

Riesgos Globales Seleccionados por Verosimilitud, Impacto, Limitantes de Inversión y Vulnerabilidad en el Perú - 2017

\begin{tabular}{|l|l|c|c|c|c|}
\hline Clase & \multicolumn{1}{|c|}{ Riesgo } & Verosimilitud & Impacto & Cuadrante & $\underline{\text { Rel. Inv. Perú }}$ \\
\hline Econ & Burbujas Económicas & 5.07 & 3.43 & II & $11.6 \%$ \\
\hline Econ & Falla Instituciones Financieras & 4.67 & 3.48 & III & $11.6 \%$ \\
\hline Econ & Crisis Fiscal & 4.67 & 3.48 & III & $16.3 \%$ \\
\hline Econ & Desempleo Subempleo & 4.87 & 3.55 & III & $37.2 \%$ \\
\hline Econ & Comercio ilicito & 5.46 & 3.14 & II & $41.9 \%$ \\
\hline Econ & Shock Precios Energia & 4.63 & 3.33 & I & $18.6 \%$ \\
\hline Amb & Eventos climatologicos extremos & 5.88 & 3.82 & IV & $24.4 \%$ \\
\hline Amb & Fracaso en mitigación/adaptación-cambio climatico & 5.18 & 3.67 & IV & $18.6 \%$ \\
\hline Amb & Desastres naturales & 5.61 & 3.77 & IV & $16.3 \%$ \\
\hline Soc & Fracaso Planificación urbana & 4.73 & 2.99 & I & $16.3 \%$ \\
\hline Soc & Crisis del agua & 4.93 & 3.77 & IV & $17.4 \%$ \\
\hline Geo & Fracaso en la gobernanza nacional & 5.18 & 3.51 & IV & $57.0 \%$ \\
\hline Geo & Colapso o crisis de los estados & 5.01 & 3.41 & II & $22.1 \%$ \\
\hline Tec & Incidentes masivo de fraude / robo de datos & 5.56 & 3.27 & II & $14.0 \%$ \\
\hline
\end{tabular}

Nota. Adaptado de “The Global Risks. Report 2017," por World Economic Forum, 2017.

\subsection{Los riesgos globales, efectos esperados en la economía peruana}

Para detectar los efectos esperados, expresados como riesgos locales, se analizará cada riesgo seleccionado a la luz de la teoría o basada en evidencia empírica, plasmándose estos en diagramas causales ${ }^{7}$. Se buscará, así,

7 El Diagrama Causal es un diagrama que recoge los elementos clave del Sistema y las relaciones entre ellos. Empiezan con versiones que poco a poco se van aproximando a la complejidad del modelo. 
JESÚS CHÁVEZ VILLARROEL

la interconexión de las relaciones de riesgo global con los efectos-riesgo local, independientemente de la vulnerabilidad (ver Anexo, Tabla 4). Estos diagramas causales tiene la propiedad de no representar relaciones lineales, por el contrario, en ellos se encuentran bucles o ciclos, propiedad que poseen un grafo.

En este caso, el efecto-riesgo local es función de los riesgos globales y de los indicadores de vulnerabilidad. No obstante, al mismo tiempo, estos factores determinantes del efecto-riesgo local, se encontrarían relacionados. De esa manera, cuando se construye el gráfico de relaciones entre los riesgos globales y los índices de vulnerabilidad local, aplicando un algoritmo de agrupamiento, se encontró clústers muy marcados. En estos, existe una fuerte centralidad de los riesgos globales del sector tecnológico, los que a su vez tienen una incidencia directa sobre la vulnerabilidades relacionadas a fragilidad social dada por los siguientes factores: (a) la desigualdad, (b) dependencia de ayuda, (c) la resiliencia o falta de reacción dada por la gobernanza, (d) comunicaciones, (e) infraestructura física, (f) gestión del riesgo, (g) control de la corrupción, (h) manejo de la infraestructura y, por último, (i) calidad de la gestión logística. Los otros riesgos forman también grupos, los económicos, los cuales se relacionan con los indicadores de resiliencia en el sector económico. Por el lado de los riesgos sociales, se asocian a los indicadores de fragilidad y los riesgos políticos se asocian con los indicadores de resiliencia política. Por tanto, el grafo revela una concentración y relación de los riesgos y la vulnerabilidad de acuerdo con el sector al que pertenecen.

Por el lado de los indicadores de vulnerabilidad destacan las asociadas a la resiliencia. Se muestra, de ese modo, un mayor grado en los indicadores asociados al contexto político y de gestión: gobernanza, comunicaciones e infraestructura física. Estos datos se detallarán en la Figura 2, elaborada mediante el software Gephi. 


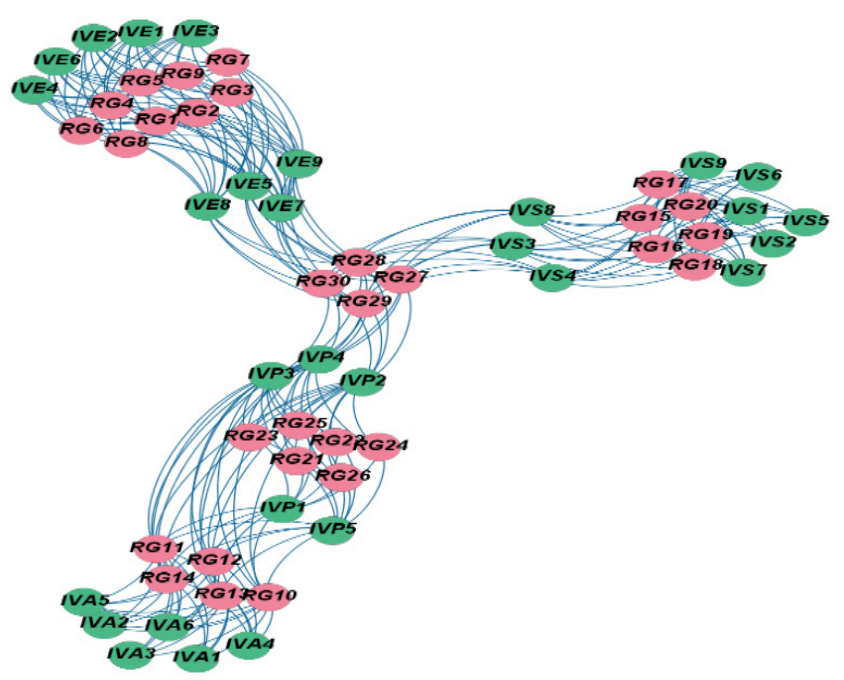

Figura 2. Relaciones del riesgo global y vulnerabilidad local - 2017. Adaptado de “The Global Risks. Report 2017," por World Economic Forum, 2017.

\subsection{Relaciones de los efectos-riesgos locales sobre las tenden- cias y riesgos globales}

En primer lugar, se demostrará que la distribución dentro de la red de los nodos (Efectos - Riesgos Locales, 48), va cambiando conforme estos se fueron relacionando con los Riesgos Globales (14) y estos con las Tendencias Globales (13). Para ello, se mostrará los gráficos de la redes, agrupados mediante el algoritmo ForceAtlas2 (algoritmo de agrupamiento en comunidades) con apoyo del software Gephi. En dicho grafo claramente se observa la conformación de comunidades (ver Figura 3).

$\mathrm{Al}$ incluir en la red las relaciones con los Riesgos Globales, quienes mantienen su comunidad son los efectos-riesgos locales ambientales. Los 
JESÚS CHÁVEZ VILLARROEL

económicos se subdividen en otras comunidades incluyendo en estas a los riesgos globales, de acuerdo al sector de pertenencia. Aunque los riesgos globales presentan influencias no solo en su sector, por ejemplo el riesgo global RGA2 (fracaso en la adaptación-mitigación al cambio climático), influyen en la comunidad de efectos ambientales y en otra comunidad dada por riesgos sociales, pues este riesgo global mantiene relación con los riesgos globales sociales. Por tanto, la comparación de la distribución de comunidades de los efectos-riesgos locales, se ve influenciada por las relaciones que mantienen con los riesgos globales.

A su vez, se presentará la red en la cual se ha incluido a las tendencias globales (tendencias, riesgos globales y efectos-riesgos locales). Ahora también se observará en la gráfica de la red que las comunidades cambian y estas disminuyen en número. Se vuelven, igualmente, más densas (aumento de los nodos). Así, llama la atención la comunidad referida a los efectos ambientales, la cual mantiene su comunidad, siendo esta influencia por todos los riesgos globales ambientales y las tendencias 3, 4, 13 (cambio climático, degradación del medio ambiente, aumento de la urbanización), además de presentar estas tendencias en otras comunidades. La comunidad más pequeña se encuentra compuesta por RLE02 y RLP02 (aumento del comercio ilícito y falla en la seguridad nacional y empresarial), comunidad en la cual se ubica el riesgo global fraude/robo de datos y la tendencia dependencia cibernética. Por su parte, la comunidad más grande se encuentra compuesta por los efectos económicos, políticos y tecnológicos. $\mathrm{Al}$ mismo tiempo, en esta misma comunidad aparecen riesgos globales económicos, geopolíticos, y la mayor parte de las tendencias. De igual modo, los efectos sociales se encuentran en diferentes comunidades donde se combinan con los efectos económicos ambientales y políticos. A continuación, la Figura 3, echa a partir del software Gephi, ilustrará lo dicho anteriormente. 


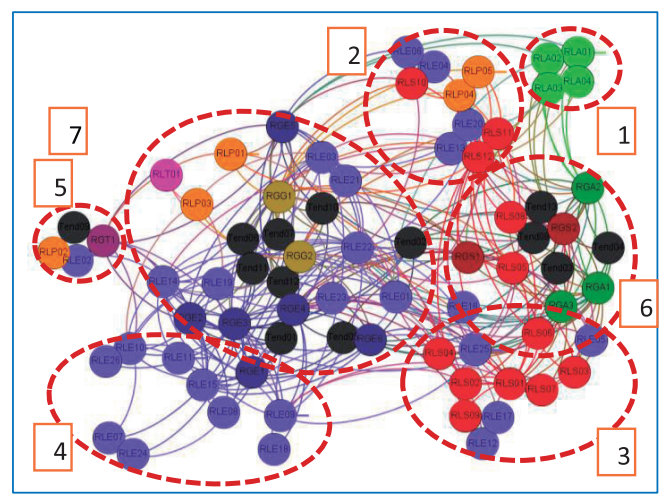

Figura 3. Red de las relaciones tendencias, riesgo global y el efecto-riesgo local -2017. Adaptado de "The Global Risks. Report 2017," por World Economic Forum, 2017.

A partir de estas gráficas se evidencia la hipótesis de la influencia que tendrían las tendencias y los riesgos globales (como amenaza) sobre los efectos-riesgos locales. Asimismo, se evidencia que la agrupación es de acuerdo con el sector, pues, si bien es cierto, existe agrupamiento de acuerdo al sector, pero también se observa influencia de enlaces entre comunidades. Esto hace pensar que la activación de un riesgo global es influenciada por las tendencias. Ellas, a su vez, activarían e incidirían directamente en los riesgos locales, los cuales, por un proceso en cadena, influiría en otros. En adición, la prueba de hipótesis se mostrará en el anexo.

\section{Discusión}

Del análisis, basado en antecedentes, literatura o teoría, y aunado con la construcción de diagramas causales (propios de la dinámica de sistemas), se identificaron 48 efectos-riesgos locales. Estos se distribuyeron en diferentes dimensiones (ambiental, económico, 
JESÚS CHÁVEZ VILLARROEL

social, político y tecnológico), efectos-riesgos locales que se concentran en su mayoría en los sectores económicos (26) y social (12). De igual manera, se identificaron efectos-riesgos locales en la dimensión política (5), ambiental (4) y tecnológica (1). Dicha identificación se agrupó por número, no así por grado de relación (entrada-salida), intermediación, centralidad y probabilidad de ocurrencia frente a la activación de uno o más riesgos globales.

De acuerdo con el acopio de las estadísticas sobre las variables de estudio y con la aplicación de procedimientos, se estimó para Perú el índice de riesgo en 4.1 (en un rango de 0 a 10). Dicho índice provino de la exposición (5.2) y fragilidad (2.8), así como de la resiliencia y la falta de capacidad de recuperación (4.6). Todos ellos se mantuvieron en este nivel y grados de clasificación medio desde los años 2013 al 2017.

Para el caso de los efectos-riesgo locales se estima el índice de riesgo condicionado a la vulnerabilidad para cada efecto-riesgo global. Tales valores se encuentran en un rango de 3 a 6.5, con un promedio de 3.96 y con muy baja variabilidad (19.5\%), colocando al país en un grado medio bajo. Para el caso del índice de riesgo por riesgo global, la estimación establece un rango entre 4.27 a 6.19, con un promedio de 4.93 y una variabilidad más baja que la anterior (9.4\%). Esto coloca al país en un grado de riesgo medio.

En la misma línea se ha identificado las siguientes vulnerabilidades: (a) exposición física a inundaciones y tsunamis, (b) producto per cápita, (c) manejo del riesgo político, (d) control de la corrupción, (e) manejo de la infraestructura pública, (f) calidad en el manejo de la logística, (g) gobernanza, (h) comunicaciones y, finalmente, (i) acceso a los cuidados y atención de salud. Todas las anteriores han sido consideradas como las poseedoras de un alto grado de relación (salida), centralidad e importancia con los efectos-riesgos locales. Por el lado de los efectos-riesgos locales, estos 
se identificaron en el siguiente listado: (a) aumento en el gasto y deuda, lo que conlleva a la disminución de la inversión pública; (b) salida de capitales, lo cual implica disminución de la producción-crecimiento; (c) aumento de epidemias, en relación a morbilidad-mortalidad y consecuente disminución de la seguridad y salud social; (d) falla en los servicios públicos y programas sociales; (e) incremento masivo de la migración; (f) incremento de la pobreza, desigualdad y vulnerabilidad. Todos estos pueden ser calificados como componentes de alto grado de relación (entrada-salida), centralidad, intermediación, probabilidad de participación y centralidad dentro de su ruta de relaciones.

Por otro lado, debe mencionarse las tendencias globales. Estas se detallarán a continuación: (a) envejecimiento poblacional, (b) cambio en la gobernanza internacional, (c) cambio climático, (d) aumento y movilidad geográfica, (e) cambios en las estructuras de poder, (f) las tendencias que inciden o influyen sobre los riesgos globales, tanto por su grado de relación (salida) y centralidad y agrupamiento en comunidades en conjunto con los riesgos globales. Dichas comunidades aumentan o aceleran la probabilidad de ocurrencia y, por ende, el impacto sobre los países expuestos a estos riesgos globales. Es en este marco, entonces, que se puede tomar el caso del Perú.

Seguidamente, de la conformación de la red de relaciones entre tendencias, riesgos globales y efectos-riesgos locales, se identificaron las siguientes tendencias: (a) envejecimiento poblacional, (b) cambio en la gobernanza internacional, (c) cambio climático, (d) aumento y movilidad geográfica y (e) cambios en las estructuras de poder. Las tendencias que inciden o influyen sobre los riesgos globales e indirectamente (a través de los riesgos globales) sobre los efectos-riesgos locales, tanto por su grado de relación (salida) y centralidad, son los que siguen: (a) alto desempleosubempleo, (b) eventos climatológicos (c) extremos, (d) fracaso en la 
mitigación/adaptación al cambio climático y (e) colapso o crisis de Estado. Estos riesgos globales poseen un alto grado de relación (salida), centralidad, intermediación, probabilidad de participación y centralidad en su ruta de relaciones sobre los efectos-riesgos locales.

Después, para el caso de los efectos-riesgos locales, se identificaron los siguientes componentes: (a) aumento del gasto, deuda y disminución de la inversión pública; (b) aumento del desempleo-subempleo; (c) descenso de compra venta, tarjetización y transacciones en línea; (d) disminución de las utilidades de las empresas, base y recaudación tributaria; (e) disminución del crecimiento-producción; (f) incremento de precios, como efectosriesgos locales en la dimensión económica, ( $\mathrm{g}$ ) aumento de epidemias, morbilidad-mortalidad como un efecto-riesgo local en la dimensión social. Con estos factores de riesgo disminuye la seguridad y salud social, además del incremento de la pobreza, desigualdad y vulnerabilidad. Todos estos efectos-riesgos locales son los que poseen mayor grado de relación, centralidad, intermediación, probabilidad de participación y centralidad en su ruta de relaciones.

La principal limitación que se tuvo se relacionó con el marco conceptual al no encontrarse teorías o metodologías que traten los riesgos globales como variables independientes y en especial con un análisis enfocado en las relaciones. Por ello, entre otros, se debe ampliar las investigaciones en torno a incluir pesos en las relaciones o enlaces. Al mismo tiempo, estos deben realizarse por grupos multidisciplinarios, dada las dimensiones en los que se encuentran distribuidos los riesgos. 


\section{Conclusiones}

Basado en los criterios de indicador de riesgo y limitaciones de los riesgos globales para realizar inversiones y negocios en Perú, se identificaron 14 riesgos globales que afectarían con alta probabilidad e impacto a la economía peruana. Estos son los que siguen: (a) burbujas económicas, (b) falla en mecanismos del sistema financiero, (c) crisis fiscal, (d) desempleosubempleo, (e) comercio ilícito, (f) shock en el precio de las energías, (g) eventos climatológicos extremos, (h) fracaso en la mitigación/adaptación al cambio climático, (i) desastres naturales, (j) fracaso en la planificación urbana, (k) crisis por el agua, (l) fracaso de la gobernanza nacional, (m) colapso o crisis de los estados y (n) incidentes masivos de fraude/robo de datos.

$\mathrm{Al}$ relacionar el índice de riesgo por vulnerabilidad frente al índice por riesgo global de la regresión, se encuentra un coeficiente estimado en 0.5772 , el cual es un coeficiente significativo. Esta conclusión lleva a evidenciar la segunda hipótesis, tal es así que el riesgo se incrementa en la medida que sube el índice de vulnerabilidad frente al riesgo global.

La conformación de la red de relaciones entre tendencias, riesgos globales y efectos-riesgos locales, permitieron identificar las siguientes tendencias: (a) envejecimiento poblacional, (b) cambio en la gobernanza internacional, (c) cambio climático, (d) aumento y movilidad geográfica, (e) cambios en las estructuras de poder y ( $f$ ) las tendencias que inciden o influyen sobre los riesgos globales. Así también, se identificaron los siguientes riesgos globales: (a) alto desempleo-subempleo, (b) eventos climatológicos extremos, (c) fracaso en la mitigación/adaptación al cambio climático, (d) colapso o crisis de Estado y (e) los riesgos globales que poseen un alto grado de relación sobre los efectos-riesgos locales. Dichos datos corroboran la cuarta hipótesis. 
Para el caso de los efectos-riesgos locales, se identificó el siguiente conjunto: (a) aumento del gasto, deuda y disminución de la inversión pública; (b) aumento del desempleo-subempleo; (c) descenso de compra venta, tarjetización y transacciones en línea; (d) disminución de las utilidades de las empresas, base y recaudación tributaria; (e) disminución del crecimiento-producción; (f) incremento de precios; (g) aumento de epidemias, morbilidad-mortalidad, disminuye la seguridad y salud social; $y$ (h) incremento de la pobreza, desigualdad y vulnerabilidad. 


\section{Referencias}

Acevedo, A., \& Vargas, F. (junio de 2000). Sociología del riesgo de Niklas Luhmann. Estudio de las culturas contemporáneas, 6(11), 14-15.

Beck, U. (1993). Teoría de la modernización reflexiva. En A. Giddens, Z. Bauman, N. Luhmann \& U. Beck, Las consecuencias perversas de la modernidad. Modernidad, contingencia y riesgo. Barcelona, España: Anthropos.

Beck, U. (2002). La sociedad del riesgo global. Madrid, Espańa: Siglo XXI.

Cardona, O. \& Barbat, A. (2001). Conceptos de amenaza, vulnerabilidad y riesgo. En O. Cardona (Ed.), Estimación holistica del riesgo sismico utilizando sistemas dinámicos complejos (pp. 5-20). Barcelona, España: Universitat Politècnica de Catalunya. Recuperado de https://www. researchgate.net/profile/Omar_Cardona/publication/277163871_ Estimacion_holistica_del_riesgo_sismico_utilizando_sistemas_ dinamicos_complejos/links/57b28ddc08ae15c76cbb40a3/ Estimacion-holistica-del-riesgo-sismico-utilizando-sistemasdinamicos-complejos.pdf

Casanova, L. (2010). Los Nuevos Protagonistas del Sur: Las multinacionales emergentes latinoamericanas. Foreign Affairs Latinoamérica, 10(1), 11-20.

Coburn, A. W. X., \& Spence, R. J. S. (1992). Vulnerabilidady evaluación del

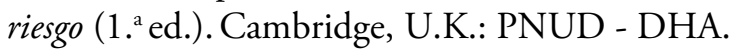

Furht, B. (2010). Handbook of Social Network Technologies and Applications. London, United Kingdom: Springer.

Gaba, E. (2013). La crisis internacional y sus efectos sobre mercados emergentes: repasando los manuales. Revista de Investigación en Modelos Financieros, 1(2), 1-7.

Gallego, A. (noviembre-diciembre de 2011). El poder tiene nombre de emergente. Escritura pública, (72), 30-32.

García Morales, F. (julio de 2000). América Latina. Las transiciones infinitas. Globalización. Revista Mensual de Economía, Sociedad y Cultura. Recuperado de http://rcci.net/globalizacion/2000/fg132.htm

Giddens, A. (1999). La tercera vía. La renovación de la socialdemocracia. México. D.F., México: Editorial Santillana. 
JESÚS CHÁVEZ VILLARROEL

Index for Risk Management. (2017). Index for Risk Management Results 2017. USA: Autor. Recuperado de http://www.informindex.org/Portals/0/InfoRM/INFORM\%20Global\%20 Results\%20Report\%202017\%20FINAL\%20WEB. pdf?ver=2016-11-21-164053-717

Jhonsonbaugh, R. (2005). Matemáticas discretas. México D. F., México: Pearson Prentice Hall.

Luhmann, N. (1993). Sociología del riesgo (2.a ed.). México, D. F., México: Universidad Iberoamericana.

Maskrey, A. (1993). Los desastres no son naturales (pp. 11-20) Bogotá, Colombia: La Red, Tercer Mundo Editores.

Mateus, J. R., \& Braset, D. W. (marzo de 2002). La globalización, sus efectos y bondades. Economía y Desarrollo, 1(1), 65-67. Recuperado de https://kardauni08.files.wordpress.com/2010/09/ globalizacic3b3n-sus-efectos-y-bondades.pdf

Motesnitsalis, E. (2012). SocialNetworks Visualizer. Software Requirements Specification - Version 1.0. Thessaloniki, Greece: Aristotle University of Thessaloniki.

Maskrey, A. E. (1994). Navegando entre brumas. La aplicación de los sistemas de información geográfica al análisis de riesgos en América Latina. Lima, Perú: La Red. Recuperado de http://www.desenredando. org/public/libros/1998/neb/neb_todo_nov-09-2002.pdf

Paulus, N. (mayo de 2004). Del concepto de riesgo: conceptualización del riesgo en Luhmann y Beck. Revista Mad, (10), 1-66.

Recuperado de https://revistas.uchile.cl/index.php/RMAD/article/ view/14786/15125

Reyes, G. (junio de 2001). Teoría de la globalización: bases fundamentales.

Tendencias. Revista de la Facultad de Ciencias Económicas y Administrativas de la Universidad de Nariño, 7(1), 43-53.

Sánchez Gonzales, M. (2001). IX Reunión de Responsables de Política Monetaria. México, D. F., México: Banco de México.

Ugalde, O. (2012). Modelo de Riesgos Catastróficos. Modelos probabilísticos y experiencia de seguros - reaseguros de terrorismo en la India. Recuperado de http:/www.ulacit.ac.cr/files/careers/99_ ugaldeomodelosderiesgoscatastrficosporterrorismoparapublicacion.pdf 
Wasserman, S., \& Katherine, F. (1993). Social Network Analysis. Methods and Applications. Nueva York,, USA: Cambridge Press.

World Economic Forum. (2017). The Global Risks. Report 2017 - 12th Edition. Dabos: Autor. Recuperado de www.circleofblue.org/wp.../ WEF_Global_Risk_Report2017.pdf

Yamin, L. E., Ghesquiere, F., Cardona, O. D., \& Ordaz, M. G. (2013). Modelación probabilista para la gestión del riesgo de desastre. El caso de Bogotá, Colombia. Bogotá, Colombia: Banco Mundial, Universidad de los Andes. Recuperado de http://www.observatorioubogrd. $\mathrm{cl} /$ descargas/MODELACION\%20PROBABILISTICA\%20 PARA\%20LA\%20GRD.pdf 


\begin{abstract}
Anexos
Tabla 4

Perú: Sin Riesgo Local - Efecto Condicionado al Riesgo Global
\end{abstract}

\begin{tabular}{|c|c|c|}
\hline $\mathbf{R L}$ & Riesgo Global vs Riesgo Local - Efecto & Índice Riesgo \\
\hline RG1 & RGE1: Burbuja Económica; Riesgo = 6.1213 & 6.1213 \\
\hline RLE10 & Descenso de Confianza - aumento de Aversión Riesgo & 4.6409 \\
\hline RLE08 & $\begin{array}{l}\text { Aumento Tipo de Cambio, Tasa Interés, Restricciones } \\
\text { Crédito }\end{array}$ & 6.2948 \\
\hline RLE15 & $\begin{array}{l}\text { Disminuye el Flujo de Capitales e Inversión Pública } \\
\text { Privada }\end{array}$ & 4.6376 \\
\hline RLE09 & $\begin{array}{l}\text { Descenso de Compra Venta Pagos, Tarjetización y } \\
\text { Transacciones Línea }\end{array}$ & 5.9705 \\
\hline RLE22 & Disminuye Producción y Crecimiento & 4.7204 \\
\hline RLE03 & Aumento Desempleo Subempleo & 4.6220 \\
\hline RLE14 & $\begin{array}{l}\text { Disminución Utilidades Empresas, Base Tributaria, } \\
\text { Recaudación, ISC }\end{array}$ & 4.6376 \\
\hline RLE01 & $\begin{array}{l}\text { Aumenta el Gasto, Disminuye Inversión Pública y Deuda } \\
\text { Pública }\end{array}$ & 4.5931 \\
\hline RG2 & RGE2: Falla Mecanismo Sistema Financiero; Riesgo = 5.824 & 5.8240 \\
\hline RLE08 & Aumento Tipo de Cambio, Tasa Interés, Restricciones Crédito & 6.1401 \\
\hline RLE19 & Disminuye las Exportaciones & 4.7158 \\
\hline RLE10 & Descenso de Confianza - Aumento de Aversión Riesgo & 4.5268 \\
\hline RLE22 & Disminuye Producción y Crecimiento & 4.6043 \\
\hline RLE01 & $\begin{array}{l}\text { Aumenta el Gasto, Disminuye Inversión Pública y Deuda } \\
\text { Pública }\end{array}$ & 4.4802 \\
\hline RLE03 & Aumento Desempleo Subempleo & 4.5084 \\
\hline RLE14 & $\begin{array}{l}\text { Disminución Utilidades Empresas, Base Tributaria, } \\
\text { Recaudación, ISC }\end{array}$ & 4.5236 \\
\hline RLE15 & Disminuye el Flujo de Capitales e Inversión Pública Privada & 4.5236 \\
\hline
\end{tabular}


Tabla 4 (continuación)

\begin{tabular}{|c|c|c|}
\hline RG3 & RGE3: Crisis Fiscal País Clave Economía Mundial; Riesgo = 5.824 & 5.8240 \\
\hline RLE26 & Turbulencias Mercado de Capitales & 5.3535 \\
\hline RLE19 & Disminuye las Exportaciones & 4.7158 \\
\hline RLE08 & $\begin{array}{l}\text { Aumento Tipo de Cambio, Tasa Interés, Restricciones } \\
\text { Crédito }\end{array}$ & 6.1401 \\
\hline RLE03 & Aumento Desempleo Subempleo & 4.5084 \\
\hline RLE22 & Disminuye Producción y Crecimiento & 4.6043 \\
\hline RLE09 & $\begin{array}{l}\text { Descenso de Compra Venta Pagos, Tarjetización y } \\
\text { Transacciones Línea }\end{array}$ & 5.8237 \\
\hline RLE25 & $\begin{array}{l}\text { Incremento Precios, Precios Combustible, Precio } \\
\text { Transporte }\end{array}$ & 4.8100 \\
\hline RLE10 & Descenso de Confianza - aumento de Aversión Riesgo & 4.5268 \\
\hline RLE07 & Aumento Salida de Capitales & 4.3714 \\
\hline RLE24 & Incremento Costo Financiamiento Externo & 4.4768 \\
\hline RG4 & RGE4: Desempleo Subempleo; Riesgo = 6.0266 & 6.0266 \\
\hline RLE18 & Disminuye Ingreso Hogares & 4.2746 \\
\hline RLE22 & Disminuye Producción y Crecimiento & 4.6837 \\
\hline RLE09 & $\begin{array}{l}\text { Descenso de Compra Venta Pagos, Tarjetización y } \\
\text { Transacciones Línea }\end{array}$ & 5.9241 \\
\hline RLS01 & $\begin{array}{l}\text { Aumento de Epidemias, Morbilidad, Mortalidad, Salud y } \\
\text { Disminuye Seguridad Social }\end{array}$ & 4.7495 \\
\hline RLS05 & Falla Infraestructura Productiva y Vial & 5.5877 \\
\hline RLE14 & $\begin{array}{l}\text { Disminución Utilidades Empresas, Base Tributaria, } \\
\text { Recaudación, ISC }\end{array}$ & 4.6016 \\
\hline RLE15 & $\begin{array}{l}\text { Disminuye el Flujo de Capitales e Inversión Pública } \\
\text { Privada }\end{array}$ & 4.6016 \\
\hline RLSO2 & $\begin{array}{l}\text { Disminución Niveles Educación, Habilidades, Destrezas y } \\
\text { Capital Humano }\end{array}$ & 4.7351 \\
\hline RLS09 & Falla Servicios Públicos y Programas Sociales & 4.7351 \\
\hline RG5 & RGE5: Comercio Ilícito; Riesgo = 6.2985 & 6.2985 \\
\hline RLA01 & Deterioro Medio Ambiente, Flora, Fauna, Biodiversidad & 5.1657 \\
\hline RLP01 & Aumento de la Corrupción y Crisis Partidos Políticos & 4.7410 \\
\hline
\end{tabular}


JESÚS CHÁVEZ VILLARROEL

Tabla 4 (continuación)

\begin{tabular}{|c|c|c|}
\hline RLE06 & Aumento Producción llegal & 4.6632 \\
\hline RLE21 & Disminuye Producción Formal & 4.6042 \\
\hline RLE03 & Aumento Desempleo Subempleo & 4.6885 \\
\hline RLE04 & Aumento Empleo Sub Empleo Ilegal & 4.6885 \\
\hline RLS10 & Incremento de Delitos, Criminalidad, Violencia Familiar & 4.6307 \\
\hline RLE22 & Disminuye Producción y Crecimiento & 4.7882 \\
\hline RLE14 & $\begin{array}{l}\text { Disminución Utilidades Empresas, Base Tributaria, } \\
\text { Recaudación, ISC }\end{array}$ & 4.7043 \\
\hline RLE15 & $\begin{array}{l}\text { Disminuye el Flujo de Capitales e Inversión Pública } \\
\text { Privada }\end{array}$ & 4.7043 \\
\hline RLA02 & Disminución de Áreas Habitables y Espacios Saludables & 4.8312 \\
\hline RG6 & RGE6: Shock Precio Combustibles; Riesgo = 5.7031 & 5.7031 \\
\hline RLE25 & $\begin{array}{l}\text { Incremento Precios, Precios Combustible, Precio } \\
\text { Transporte }\end{array}$ & 4.7598 \\
\hline RLE11 & $\begin{array}{l}\text { Disminución Inversión en Exploración y Proyectos } \\
\text { Hidrocarburos }\end{array}$ & 4.8094 \\
\hline RLE11 & $\begin{array}{l}\text { Disminución Inversión en Exploración y Proyectos } \\
\text { Hidrocarburos }\end{array}$ & 4.8094 \\
\hline RLE14 & $\begin{array}{l}\text { Disminución Utilidades Empresas, Base Tributaria, } \\
\text { Recaudación, ISC }\end{array}$ & 4.4764 \\
\hline RLE15 & $\begin{array}{l}\text { Disminuye el Flujo de Capitales e Inversión Pública } \\
\text { Privada }\end{array}$ & 4.4764 \\
\hline RG7 & RGA1: Eventos Climatológicos Extremos; Riesgo = 7.0119 & 7.0119 \\
\hline RLS03 & $\begin{array}{l}\text { Disminución Stock Viviendas y Aumento Viviendas } \\
\text { Vulnerables }\end{array}$ & 5.1075 \\
\hline RLS07 & Falla Infraestructura Servicios Salud & 5.6244 \\
\hline RLS08 & Falla Infraestructura Servicios Seguridad Ciudadana & 6.0203 \\
\hline RLSO4 & Falla Infraestructura Cadena Alimentaria y Escasez & 5.0521 \\
\hline RLS06 & Falla Infraestructura Servicios Básicos ADAE & 5.8733 \\
\hline RLS05 & Falla Infraestructura Productiva y Vial & 6.0272 \\
\hline RLE22 & Disminuye Producción y Crecimiento & 5.0521 \\
\hline
\end{tabular}


Tabla 4 (continuación)

\begin{tabular}{|c|c|c|}
\hline RLS01 & $\begin{array}{l}\text { Aumento de Epidemias, Morbilidad, Mortalidad, Salud y } \\
\text { Disminuye Seguridad Social }\end{array}$ & 5.1231 \\
\hline RLE16 & Disminuye Fondo Estabilización Fiscal & 5.3744 \\
\hline RLE01 & $\begin{array}{l}\text { Aumenta el Gasto, Disminuye Inversión Pública y Deuda } \\
\text { Pública }\end{array}$ & 4.9160 \\
\hline RLE25 & $\begin{array}{l}\text { Incremento Precios, Precios Combustible, Precio } \\
\text { Transporte }\end{array}$ & 5.2778 \\
\hline RG8 & $\begin{array}{l}\text { RGA2: Fracaso Mitigación Adaptación Cambio Climático; } \\
\qquad \text { Riesgo }=6.3483\end{array}$ & 6.3483 \\
\hline RLA04 & Perdida Superficie Glaciar y Suelo Agrícola & 5.0288 \\
\hline RLA01 & Deterioro Medio Ambiente, Flora, Fauna, Biodiversidad & 5.1861 \\
\hline RLS05 & Falla Infraestructura Productiva y Vial & 5.7350 \\
\hline RLA03 & Disminuye Reservas de Agua & 4.7976 \\
\hline RLA02 & Disminución de Áreas Habitables y Espacios Saludables & 4.8503 \\
\hline RLS11 & Incremento Masivo Migración & 4.7769 \\
\hline RLE20 & Disminuye Producción Agrícola & 4.8710 \\
\hline RLE22 & Disminuye Producción y Crecimiento & 4.8071 \\
\hline RLE25 & $\begin{array}{l}\text { Incremento Precios, Precios Combustible, Precio } \\
\text { Transporte }\end{array}$ & 5.0218 \\
\hline RLE03 & Aumento Desempleo Subempleo & 4.7070 \\
\hline RLS12 & Incremento Pobreza, Desigualdad, Vulnerabilidad & 4.8598 \\
\hline RG9 & RGA3: Eventos Naturales Sismos Tsunamis; Riesgo = 6.7591 & 6.7591 \\
\hline RLS03 & $\begin{array}{l}\text { Disminución Stock Viviendas y Aumento Viviendas } \\
\text { Vulnerables }\end{array}$ & 5.0146 \\
\hline RLS07 & Falla Infraestructura Servicios Salud & 5.5221 \\
\hline RLS08 & Falla Infraestructura Servicios Seguridad Ciudadana & 5.9107 \\
\hline RLS01 & $\begin{array}{l}\text { Aumento de Epidemias, Morbilidad, Mortalidad, Salud y } \\
\text { Disminuye Seguridad Social }\end{array}$ & 5.0299 \\
\hline RLS04 & Falla Infraestructura Cadena Alimentaria y Escasez & 4.9602 \\
\hline RLS06 & Falla Infraestructura Servicios Básicos ADAE & 5.7664 \\
\hline RLS05 & Falla Infraestructura Productiva y Vial & 5.9176 \\
\hline
\end{tabular}


JESÚS CHÁVEZ VILLARROEL

Tabla 4 (continuación)

\begin{tabular}{|c|c|c|}
\hline RLE22 & Disminuye Producción y Crecimiento & 4.9602 \\
\hline RLE25 & $\begin{array}{l}\text { Incremento Precios, Precios Combustible, Precio } \\
\text { Transporte }\end{array}$ & 5.1817 \\
\hline RLE16 & Disminuye Fondo Estabilización Fiscal & 5.2766 \\
\hline RLE01 & $\begin{array}{l}\text { Aumenta el Gasto, Disminuye Inversión Pública y Deuda } \\
\text { Pública }\end{array}$ & 4.8265 \\
\hline RG10 & RGS1: Fracaso en la Planificación Urbana; Riesgo = 5.5958 & 5.5958 \\
\hline RLA04 & Perdida Superficie Glaciar y Suelo Agrícola & 4.7214 \\
\hline RLS03 & $\begin{array}{l}\text { Disminución Stock Viviendas y Aumento Viviendas } \\
\text { Vulnerables }\end{array}$ & 4.5627 \\
\hline RLS05 & Falla Infraestructura Productiva y Vial & 5.3843 \\
\hline RLE05 & $\begin{array}{l}\text { Aumento Fuerte Presupuesto Público Prevención } \\
\text { Mitigación }\end{array}$ & 5.5258 \\
\hline RLS06 & Falla Infraestructura Servicios Básicos ADAE & 5.2468 \\
\hline RLS12 & Incremento Pobreza, Desigualdad, Vulnerabilidad & 4.5627 \\
\hline RG11 & RGS2: Crisis Agua; Riesgo = 6.2063 & 6.2063 \\
\hline RLA03 & Disminuye Reservas de Agua & 4.7436 \\
\hline RLA01 & Deterioro Medio Ambiente, Flora, Fauna, Biodiversidad & 5.1277 \\
\hline RLA02 & Disminución de Áreas Habitables y Espacios Saludables & 4.7957 \\
\hline RLS11 & Incremento Masivo Migración & 4.7232 \\
\hline RLS01 & $\begin{array}{l}\text { Aumento de Epidemias, Morbilidad, Mortalidad, Salud y } \\
\text { Disminuye Seguridad Social }\end{array}$ & 4.8198 \\
\hline RLS02 & $\begin{array}{l}\text { Disminución Niveles Educación, Habilidades, Destrezas y } \\
\text { Capital Humano }\end{array}$ & 4.8051 \\
\hline RLE20 & Disminuye Producción Agrícola & 4.8162 \\
\hline RLE25 & $\begin{array}{l}\text { Incremento Precios, Precios Combustible, Precio } \\
\text { Transporte }\end{array}$ & 4.9653 \\
\hline RLE03 & Aumento Desempleo Subempleo & 4.6540 \\
\hline RLS12 & Incremento Pobreza, Desigualdad, Vulnerabilidad & 4.8051 \\
\hline RG12 & RGG1: Fracaso Gobernanza Nacional; Riesgo = 6.2572 & 6.2572 \\
\hline RLP01 & Aumento de la Corrupción y Crisis Partidos Políticos & 4.7255 \\
\hline
\end{tabular}


Tabla 4 (continuación)

\begin{tabular}{|c|c|c|}
\hline RLP05 & Perdida de Libertad, Inclusión, Justicia & 4.7553 \\
\hline RLP04 & Perdida de Legitimidad Poder & 4.4216 \\
\hline RLS05 & Falla Infraestructura Productiva y Vial & 5.6936 \\
\hline RLE23 & Falla Regulación Supervisión & 5.0896 \\
\hline RLE22 & Disminuye Producción y Crecimiento & 4.7725 \\
\hline RLS10 & Incremento de Delitos, Criminalidad, Violencia Familiar & 4.6155 \\
\hline RLS04 & Falla Infraestructura Cadena Alimentaria y Escasez & 4.7725 \\
\hline RLE03 & Aumento Desempleo Subempleo & 4.6731 \\
\hline RLS12 & Incremento Pobreza, Desigualdad, Vulnerabilidad & 4.8248 \\
\hline RG13 & RGG2: Colapso Crisis Estados; Riesgo = 6.0604 & 6.0604 \\
\hline RLP03 & Fallas Políticas Públicas y de Exterior, TLC & 4.4592 \\
\hline RLE23 & Falla Regulación Supervisión & 5.0089 \\
\hline RLE19 & Disminuye las Exportaciones & 4.8105 \\
\hline RLE13 & Disminución Remesas & 4.6532 \\
\hline RLE12 & Disminución Precios Activos Bolsa AFPs & 4.6178 \\
\hline RLE17 & Disminuye Fondo Previsionales & 5.6890 \\
\hline RLS11 & Incremento Masivo Migración & 4.6673 \\
\hline RLE22 & Disminuye Producción y Crecimiento & 4.6968 \\
\hline RLE14 & $\begin{array}{l}\text { Disminución Utilidades Empresas, Base Tributaria, } \\
\text { Recaudación, ISC }\end{array}$ & 4.6145 \\
\hline RLE03 & Aumento Desempleo Subempleo & 4.5990 \\
\hline RLS01 & $\begin{array}{l}\text { Aumento de Epidemias, Morbilidad, Mortalidad, Salud y } \\
\text { Disminuye Seguridad Social }\end{array}$ & 4.7629 \\
\hline RLE01 & $\begin{array}{l}\text { Aumenta el Gasto, Disminuye Inversión Pública y Deuda } \\
\text { Pública }\end{array}$ & 4.5702 \\
\hline RLS12 & Incremento Pobreza, Desigualdad, Vulnerabilidad & 4.7483 \\
\hline RLT01 & Falla TIC - SI & 5.5975 \\
\hline RG14 & RGT1: Incidentes Masivos Fraude Robo Datos; Riesgo = 6.4503 & 6.4503 \\
\hline RLE09 & $\begin{array}{l}\text { Descenso de Compra Venta Pagos, Tarjetización y } \\
\text { Transacciones Línea }\end{array}$ & 6.1289 \\
\hline RLP02 & Falla Seguridad Nacional y Empresarial & 4.4461 \\
\hline
\end{tabular}


Tabla 4 (continuación)

\begin{tabular}{lll} 
RLE10 & Descenso de Confianza - aumento de Aversión Riesgo & 4.7640 \\
RLE02 & Aumento del Comercio llícito & 4.7465 \\
RLP01 & $\begin{array}{l}\text { Aumento de la Corrupción y Crisis Partidos Políticos } \\
\text { RLE14 }\end{array}$ & $\begin{array}{l}\text { Disminución Utilidades Empresas, Base Tributaria, } \\
\text { Recaudación, ISC }\end{array}$ \\
\hline
\end{tabular}

Nota. Adaptado de “The Global Risks. Report 2017,” por World Economic Forum, 2017. 


\section{Prueba de hipótesis ${ }^{8}$}

\section{Hipótesis}

Con la globalización económica, la industria se trasladó a los países emergentes, por lo cual existe una línea de asociación o relación inversa entre el riesgo y el nivel de riqueza de un país. Por tanto, los efectos de los riesgos globales, en una economía con mercado emergente como el Perú, son vistos como los riesgos locales que se generan a partir de los riesgos globales en interacción con la vulnerabilidad, concentrándose y centrándose estos efectos-riesgos locales en los sectores económicos y sociales.

La hipótesis, está compuesta por tres proposiciones:

- Relación indirecta entre el Riesgo y el Nivel de Riqueza.

- Relación significativa de la vulnerabilidad local y el riesgo global.

- Concentración y centralización en los sectores económicos y sociales de los efectos-riesgos locales.

En virtud a lo anterior, se realizaron procedimientos que permitieron corroborar la hipótesis general. En primer lugar, se presenta la relación entre el índice social y económico para 191 países que componen la base de

8 En la prueba de las hipótesis se empleó la teoría de grafos y, como metodología de análisis de relaciones, lo que se conoce como "Análisis de Redes Sociales". A esta última se le ha considerado como técnicas no paramétricas dentro de la teoría estadística de contrastación de hipótesis. Para la construcción de los diagramas y estadísticas, se utilizaron softwares libres, tales como Gephi y SocNetV. De igual modo, las estadísticas son referidas al grado, modularidad, excentricidad, entre otras. Los resultados serán analizados en las páginas que siguen. 
INFORM - INDEX 2017 . El índice socioeconómico ha sido reescalado en el intervalo de 0 a 10. Sin embargo, debe entenderse que, a mayor índice, el país posee mejores condiciones socioeconómicas. Por otro lado, el índice de riesgo para los países también es dado en el rango de 0 a 10, pero en este se entiende que un índice más alto implica una mayor postura o exposición al riesgo global. Asimismo, los datos corresponden para un panel de 191 países en los años 2013 a 2017. Esto podrá apreciarse en la Figura 4, la cual requirió, para su elaboración, del software Stata.

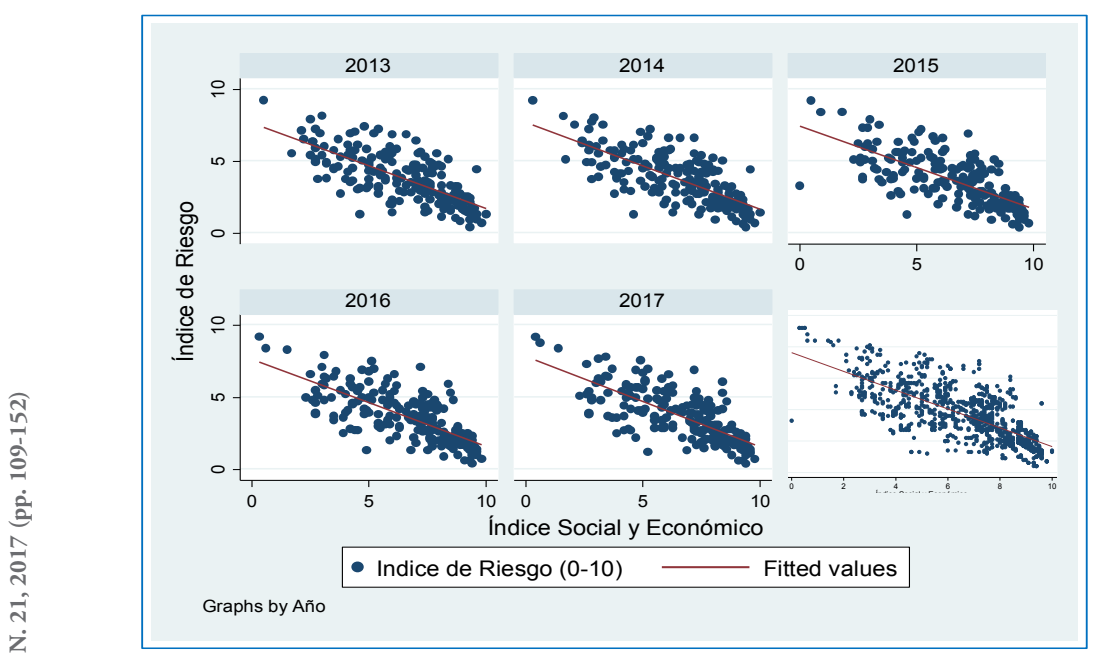

Figura 4. Diagrama de dispersión del índice socio económico vs índice de riesgo 2013 a 2017. Adaptado de “The Global Risks. Report 2017," por World Economic Forum, 2017.

${ }^{9}$ Para más información, consultar el siguiente enlace: http://www.inform-index.org/ 
El panel de diagramas de dispersión de la Figura 4, correspondiente al índice de riesgo sobre el índice socio económico de cada país, muestra una clara relación inversa, de tal manera que a medida que el índice socioeconómico (como indicador o variable proxy del nivel de riqueza) se incrementa el índice de riesgo disminuye. Por otro lado, la regresión en panel con efectos fijos en torno a la Figura 5 (hecha con el software Strata), y correspondiente al índice de riesgo sobre el índice socio económico, muestra un coeficiente negativo e igual a -0.5991631. Además, la variable asociada a este estimador (índice socio económico) es significativo, por tanto, el modelo en su conjunto también lo es $(\operatorname{Prob}(\mathrm{F}>\mathrm{Fc}=1023.39)=0.0000)$. Gracias a esto, se probaría la relación inversa entre el nivel de riqueza y el riesgo, con lo que quedaría en claro que, mientras un país sea más pobre, más expuesto se encontraría a los riesgos globales.

\begin{tabular}{r|rrrrrr}
\hline Risk_Index & Coef. & Std. Err. & $t$ & $\mathrm{P}>|t|$ & [95\% Conf. Interval] \\
\hline SE_Index & -.5991631 & .0187295 & -31.99 & 0.000 & -.6359191 & -.5624072 \\
_cons & 7.634439 & .1288494 & 59.25 & 0.000 & 7.381577 & 7.887302 \\
\hline sigma_u & .03643796 & & & & \\
sigma_e & 1.2270325 & & & & \\
rho & .00088108 & (fraction of variance due to u_i) & \\
\hline
\end{tabular}

F test that all $u_{-} i=0: F(4,949)=0.17$

Prob $>\mathrm{F}=0.9545$

Figura 5. Reporte regresión del índice socio económico vs índice de riesgo - 2013 a 2017. Adaptado de “The Global Risks. Report 2017," por World Economic Forum, 2017. 
Para el caso de la segunda proposición, se recurrió a la tabla de métricas del grafo riesgo global y vulnerabilidad local. Para ello, se ha usado la métrica que mide el grado de influencia (IRCC) de los riesgos globales sobre la vulnerabilidad (Wasserman, 1993). Los resultados se dan en términos en proporción y en porcentaje, tal como se verá en las Figuras 6, 7 y 8, elaboradas con el apoyo del software Stata.

A su vez, de los 30 riesgos globales, la influencia media que estos ejercerían sobre la vulnerabilidad local es de $14.94 \%$ con una desviación estándar de $8.62 \%$. Se muestra, así, la existencia de variabilidad alta en el nivel de influencia.

\begin{tabular}{r|rrrrr} 
Variable & Obs & Mean & Std. Dev. & Min & Max \\
\hline Nodo & 30 & 41.36667 & 14.29368 & 1 & 59 \\
RG & 0 & & & & \\
IRCC & 30 & .1493 & .034677 & .086 & .19 \\
IRCC1 & 30 & 14.9425 & 3.458094 & 8.621 & 18.966
\end{tabular}

Figura 6. Resumen de las métricas de los nodos riesgo global - 2017. Adaptado de “The Global Risks. Report 2017,” por World Economic Forum, 2017.

La influencia no es uniforme, son los riesgos globales ambientales los que más influencia tendrían con la vulnerabilidad local, seguida de los riesgos tecnológicos y riesgos económicos. Este aspecto se ratifica con el análisis de varianza que se realiza a las métricas de influencia por sector, en donde se observa que existe diferencia significativa en las medias de influencia por sector. 


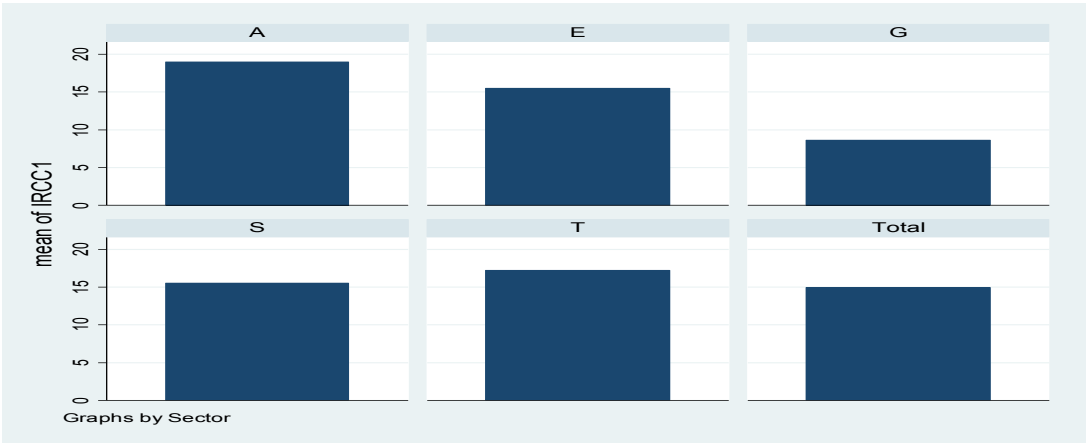

Figura 7. Influencias del riesgo global sobre la vulnerabilidad local por sectores - 2017. Adaptado de “The Global Risks. Report 2017,” por World Economic Forum, 2017.

- oneway IRCC1 Sector

\begin{tabular}{crrrrr}
\multicolumn{4}{c}{ Analysis of Variance } & & \\
Source & SS & df & MS & F & Prob $>$ F \\
\hline Between groups & 346.794049 & 4 & 86.6985122 & \\
Within groups & 0 & 25 & 0 & \\
\hline
\end{tabular}

Total $\quad 346.794049 \quad 29 \quad 11.9584155$

Figura 8. Anova de la influencia de los nodos riesgo global sobre el efecto-riesgo local por sectores - 2017. Adaptado de "The Global Risks. Report 2017," por World Economic Forum, 2017.

Por último, para probar la concentración y centralización en los sectores económicos y sociales de los efectos-riesgos locales, se construyó la tabla de frecuencias de los 48 efectos-riesgos locales. En efecto, alrededor del $80 \%$ de estos, se concentra en los sectores económico y social, muy a 
pesar que la mayor exposición es en el sector ambiental, pero los impactos son traducidos en aspectos económicos y por ende en lo social. Todo ello se ejemplificará en la Tabla 5, hecha a través de MS Excel.

Tabla 5

Distribución de los Efectos-Riesgos Locales por Sectores - 2017

\begin{tabular}{|l|r|r|}
\hline \multicolumn{1}{|c|}{ Sector } & \multicolumn{1}{|c|}{ Cuenta } & \multicolumn{1}{c|}{ Cuenta $\%$} \\
\hline Ambiental & 4 & $8.33 \%$ \\
\hline Económico & 26 & $54.17 \%$ \\
\hline Político & 5 & $10.42 \%$ \\
\hline Social & 12 & $25.00 \%$ \\
\hline Tecnológico & 1 & $2.08 \%$ \\
\hline Total general & 48 & $100.00 \%$ \\
\hline
\end{tabular}

Nota. Adaptado de “The Global Risks. Report 2017," por World Economic Forum, 2017. 